\title{
DIFFUSION TENSOR MR IMAGING EVALUATION OF THE CORPUS CALLOSUM OF PATIENTS WITH MULTIPLE SCLEROSIS
}

\author{
Fernanda Rueda ${ }^{7}$, Luiz Celso Hygino Jr $r^{2,3}$, Romeu Cortês Domingues ${ }^{4}$, \\ Cláudia C. Vasconcelos 5 , Regina M. Papais-Alvarenga ${ }^{6}$, Emerson L. Gasparetto,
}

\begin{abstract}
Objective: To evaluate the fractional anisotropy (FA) values of the normal-appearing white matter of the corpus callosum (CC) in patients with relapsing-remitting multiple sclerosis (MS). Method: Fifty-seven patients with diagnosis of relapsing-remitting MS and 47 age- and gender-matched controls were studied. A conventional MR imaging protocol and a DTI sequence were performed. One neuroradiologist placed the regions of interest (ROIs) in the FA maps in five different portions of the normal-apearing CC (rostrum, genu, anterior and posterior portion of the body and splenium) in all cases. The statistical analysis was performed with the Mann-Whitney $U$ test and $p<0.05$ was considered statistically significant. Results: The FA values were lower in the MS patients compared with the controls $(p<0.05)$ in the following $C C$ regions: rostrum $(0.720 \mathrm{vs}$ 0.819 ), anterior body ( 0.698 vs 0.752 ), posterior body ( 0.711 vs 0.759 ) and splenium ( 0.720 vs 0.880$)$. Conclusion: In this series, there was a robust decrease in the FA in all regions of the normal-appearing $\mathrm{CC}$, being significant in the rostrum, body and splenium. This finding suggests that there is a subtle and diffuse abnormality in the $\mathrm{CC}$, which could be probably related to myelin content loss, axonal damage and gliosis.
\end{abstract}

KEY WORDS: multiple sclerosis, diffusion tensor imaging, fractional anisotropy.

\begin{abstract}
Avaliação do corpo caloso em pacientes com esclerose múltipla através de imagens de RM por tensor de difusão
Resumo - Objetivo: Avaliar os valores da anisotropia fracionada (FA) da substância branca aparentemente normal do corpo caloso (CC) em pacientes com esclerose múltipla (EM) remitente recorrente. Método: 57 pacientes com diagnóstico de EM remitente recorrente e 47 controles pareados por sexo e idade foram estudados. O protocolo convencional de RM e imagens de tensor de difusão foram adquiridas. Um neurorradiologista posicionou as regiões de interesse nos mapas de FA em seis porções do CC aparentemente normal (rostro, joelho, anterior e posterior porções do corpo e esplênio) em todos os casos. A análise estatística foi realizada com o teste Mann-Whitney $\mathrm{U}$ e $\mathrm{p}<0,05$ foi considerado estatisticamente significativo. Resultados: Os valores de FA foram menores nos pacientes com EM comparados com os controles $(p<0,05)$ nas seguintes porções do CC: rostro $(0,720$ vs 0,819$)$, corpo anterior $(0,698$ vs 0,752$)$, corpo posterior $(0,711$ vs 0,759$)$ e esplênio $(0,720$ vs $0,880)$. Conclusão: Na presente série houve redução robusta na FA em todas as regiões aparentemente normais do CC, sendo significativa no rostro, corpo e esplênio. Este achado sugere que há alteração difusa no corpo caloso de pacientes com EM, provavelmente relacionada a perda da mielina, lesão axonal e gliose.
\end{abstract}

PALAVRAS-CHAVE: esclerose múltipla, imagens de tensor de difusão, anisotropia fracionada.

\footnotetext{
CDPI - Clínica de Diagnóstico Por Imagem and Department of Radiology of the University of Rio de Janeiro, Rio de Janeiro RJ, Brazil: 'Médico Residente do Serviço de Radiodiagnóstico do Hospital Universitário Clementino Fraga Filho, Universidade Federal do Rio de Janeiro, Rio de Janeiro RJ, Brazil; ${ }^{2}$ Mestrando do Programa de Pós-Graduação em Medicina (Radiologia) da Universidade Federal do Rio de Janeiro, Rio de Janeiro RJ, Brazil; ${ }^{3}$ Médico Radiologista das Clínicas CDPI - Clínica de Diagnóstico Por Imagem e Multi-Imagem, Rio de Janeiro RJ, Brazil; ${ }^{4}$ Médico Radiologista e Diretor das Clínicas CDPI - Clínica de Diagnóstico Por Imagem e Multi-Imagem, Rio de Janeiro RJ, Brazil; ${ }^{5}$ Doutoranda do Programa de Pós-Graduação em Medicina (Radiologia) da Universidade Federal do Rio de Janeiro, Rio de Janeiro RJ, Brazil; ${ }^{\circ}$ Professora Associada de Neurologia da Universidade Federal do Estado do Rio de Janeiro, Rio de Janeiro RJ, Brazil; ${ }^{7}$ Professor Adjunto de Radiologia da Faculdade de Medicina da Universidade Federal do Rio de Janeiro, Rio de Janeiro RJ, Brazil. This study was supported by the FUJB - Fundação Universitária José Bonifácio (UFRJ), FAPERJ - Fundação Carlos Chagas Filho de Amparo à Pesquisa do Estado do Rio de Janeiro and CNPq - Conselho Nacional de Desenvolvimento Científico e Tecnológico.
}

Received 3 March 2008, received in final form 27 May 2008. Accepted 16 June 2008.

Dr. Emerson L. Gasparetto - Hospital Universitário Clementino Fraga Filho da UFRJ - Rua Professor Rodolpho Paulo Rocco 255 - $21941-913$ Rio de Janeiro RJ - Brasil. E-mail: egasparetto@gmail.com 
The corpus callosum (CC) is the largest fiber bundle that connects cortical and subcortical regions of the brain'. It also interconnects both cerebral hemispheres, promoting functional integration of sensory and motor functions ${ }^{2}$. The CC is composed of many different fiber types, with varied thicknesses and myelin sheath variations $^{3}$. The classic subdivision of the $\mathrm{CC}$ was suggested by Witelson, who tried to link the crossing fibers of the related cortical areas².

The callosal tracts are frequently affected in patients with multiple sclerosis (MS), which is a demyelinating disease associated with axonal destruction and Wallerian degeneration ${ }^{3-5}$. Magnetic resonance (MR) imaging is the gold standard imaging technique for the evaluation of patients with MS. However, there are microstructural pathologic alterations in MS patients that cannot be assessed with conventional MR sequences ${ }^{1,6}$. Also, areas of normal-appearing white matter (NAWM), defined as normal signal intensity on T2-weighted images, have been shown histological abnormalities ${ }^{4,5}$. Advanced MR imaging techniques, such as MR spectroscopy and diffusion tensor imaging (DTI), have been employed for evaluating the NAWM in patients with $\mathrm{MS}^{3,5}$.

The DTI is an advanced MR imaging technique that provides unique quantitative information regarding the structural and orientational features of the central nervous system. The DTI allows the calculation of many parameters, including the mean difusibility, which is a directionally averaged measurement of the apparent diffusion coefficient, and the fractional anisotropy (FA), which summarizes the orientational dependence of the diffusivity ${ }^{7,8}$. The fractional anisotropy has been used as an advanced approach for assessing the white matter structural integrity ${ }^{6,7}$.

Many authors have investigated the NAWM of patients with MS using DTI. These studies have shown decrease of the FA values in the NAWM, probably secondary to myelin sheath and axonal destruction ${ }^{4,-11}$. These abnormalities tend to expand the extracellular space, resulting in increased diffusivity and reduced directionality $(F A)^{3}$. Although CC is a good example of NAWM, with high concentration of white matter tracts, it was poorly studied in MS patients ${ }^{1,6}$. Moreover, the reasonably defined borders of the $\mathrm{CC}$ limits inadvertent tissue class mixing, which could complicate the analysis of the NAWM ${ }^{5}$. As a result, the $C C$ is an ideal anatomical structure to evaluate the NAWM in MS patients.

This study aimed to evaluate the fractional anisotropy values of the normal-appearing white matter of the corpus callosum in patients with relapsing-remitting multiple sclerosis.

\section{METHOD}

Subjects

We retrospectively studied fifty-seven consecutive patients (32 females and 25 males; median age 36 years, standard deviation 11.6) with diagnosis of relapsing-remitting MS according to the McDonald criteria ${ }^{12}$. The control group included forty-seven volunteers ( 26 women and 14 men, median age 34 years, standard deviation 12.8), who had no clinical and imaging evidence of neurological disease. All the MS patients had been receiving medication for various periods of time when the MR imaging data was acquired. The patients and controls signed informed consent and the institutional review board of our hospital approved the study.

\section{MR imaging acquisition}

The MR imaging was performed in a 1.5T scanner (Magneton Avanto, Siemens, Germany), with a 12-channel head coil. The conventional MR imaging protocol included: coronal T2-weighed images (repetition time $(T R)=4410 \mathrm{~ms}$, echo time $(T E)=98 \mathrm{~ms}$, field of view $(F O V)=240 \mathrm{~mm}$, matrix $=320 \times 320$, section thickness $=3 \mathrm{~mm}$ ); sagittal FLAIR (TR=9950 ms, TE=100 ms, inversion time $=2500 \mathrm{~ms}, \mathrm{FOV}=220 \mathrm{~mm}$, matrix $=256 \times 256$, section thickness $=3 \mathrm{~mm}$ ), and axial and sagittal T1-weighed images with magnetization transfer before and after intravenous contrast administration $(T R=635 \mathrm{~ms}, T E=9.4 \mathrm{~ms}, \mathrm{FOV}=240 \mathrm{~mm}$, matrix $=256 \times 256$, section thickness $=5 \mathrm{~mm}$ ).

The diffusion protocol consisted of a whole-brain singleshot echo-planar imaging, with bipolar diffusion gradients applied along six noncollinear directions, $(G x, G y, G z)=\{(1,1,0)$, $(1,0,1),(0,1,1),(1,-1,0),(-1,0,1),(0,1,-1)\}$. The DTI sequence was acquired in the sagittal plane with the following parameters: $T R=3200 \mathrm{~ms}, \mathrm{TE}=95 \mathrm{~ms}$, matrix $=128 \times 128, \mathrm{FOV}=240 \mathrm{~mm}$, slice thickness $=3 \mathrm{~mm}$, no interslice gap, bandwidth $1346 \mathrm{kHz}$, EPI factor 128, echo-spacing 0.83, flip angle $90^{\circ}, 3$ averages. To optimize the measurement of diffusion in the brain, only two $b$ factors were used (b1=0 e b2 $=1000 \mathrm{~s} / \mathrm{mm}^{2}$ ).

\section{DTI post-processing and analysis}

The DTI raw data were transferred to an independent workstation (Leonardo, Siemens, Germany) and post-processed with standard software (Syngo VB13, Siemens, Germany). The FA maps were obtained as the standard index of anisotropy. An experienced neuroradiologist placed the regions of interest (ROIs) in the FA maps in five different portions of the CC (rostrum, genu, anterior and posterior portion of the body and splenium) in all cases (Figure). The size of the ROls was uniform between the subjects, measuring from 25 pixels in the rostrum to 90 pixels in the genu, body and splenium. Although all MS patients had white matter lesions seen on the conventional MR imaging, the FLAIR sequence and b0 images registered to FA maps showed no lesions in the CC within the studied ROIs. 


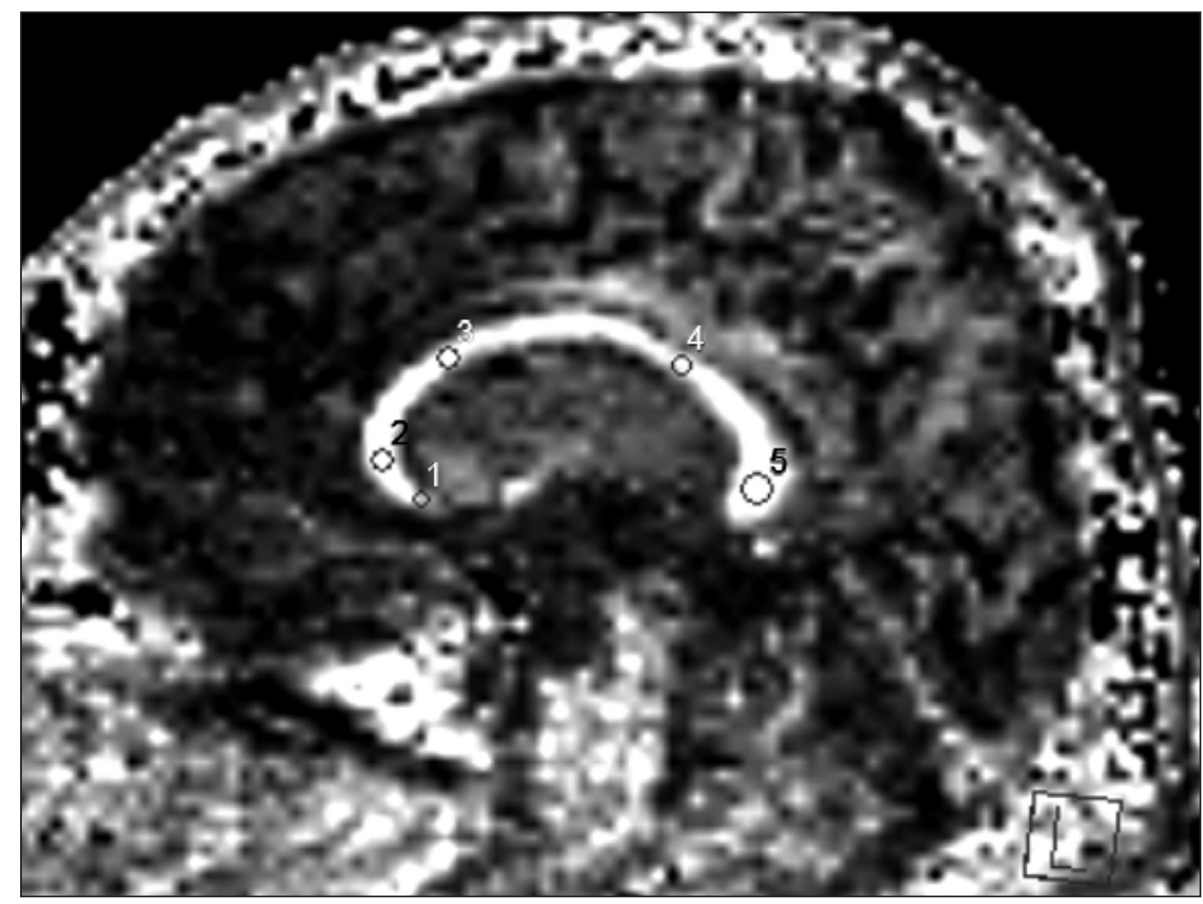

Figure. Sagittal FA map showing the position of the ROIs placed on the corpus calosum: rostrum (1), genu (2), anterior body (3), posterior body (4) and splenium (5).

\section{Statistical analysis}

The MS and control groups were compared for FA values in each studied portion of the corpus callosum. The statistical analysis was performed with the Mann-Whitney $U$ test and $p<0.05$ was considered statistically significant.

\section{RESULTS}

The mean FA values measured in the corpus callosum of MS patients and healthy controls are demonstrated in the Table. The FA values were lower in the MS patients compared with the controls in all CC regions: rostrum (0.720 vs 0.819$)$, genu (0.776 vs 0.844 ), anterior body ( 0.698 vs 0.752 ), posterior body ( 0.711 vs 0.759 ) and splenium $(0.720$ vs 0.880$)$. The FA reduction was statically significant $(p<0.05)$ in the rostrum, anterior and posterior body and in the splenium of the CC. Although the FA values in the genu of the CC were lower in the MS patients compared with the controls, this difference didn't reach statistical significance ( $p>0.05)$.

\section{DISCUSSION}

Diffusion tensor imaging is a MR imaging technique that allows measurement of the magnitude and directionality of water diffusion in tissue, providing a quantitative method for in vivo assessment of the integrity of white matter fiber tracts $^{8}$. Previous studies with DTI have demonstrated reduced anisotrophy in the demyelinating plaques and NAWM of MS patients ${ }^{3,7,9}$. In this study we assessed the utility of the DTI for the evaluation of the underlying pathological process in the CC of MS patients. Our series included fifty-seven patients with RRMS and forty-seven age- and gender-matched healthy controls. We observed global FA reduction in the CC of MS patients, being statistically significant in the rostrum, anterior and posterior body, as well as in the splenium.

Previous studies assessing the anisotropy in the NAWM of the CC of MS patients have also demonstrated reduced FA values ${ }^{1,3,6,13}$. Some authors observed FA decrease predominantly in the body of the $\mathrm{CC}^{1,6}$. Others groups

Table. Comparison of the anisotropy values in different topographies of the corpus callosum between MS patients and controls.

\begin{tabular}{lccccc}
\hline & \multicolumn{5}{c}{ Corpus callosum } \\
\cline { 2 - 6 } & Rostrum & Genu & Anterior body & Posterior body & Splenium \\
\hline MS patients (mean FA \pm SD) & $0.720 \pm 0.090$ & $0.776 \pm 0.080$ & $0.698 \pm 0.121$ & $0.711 \pm 0.112$ & $0.720 \pm 0.055$ \\
Controls (mean FA \pm SD) & $0.819 \pm 0.062$ & $0.844 \pm 0.061$ & $0.752 \pm 0.098$ & $0.759 \pm 0.096$ & $0.880 \pm 0.038$ \\
p value & $<0.05$ & $>0.05$ & $<0.05$ & $<0.05$ & $<0.05$ \\
\hline
\end{tabular}

FA, fractional anisotropy; SD, standard deviation. 
showed low FA values in the genu and splenium of the CC in MS patients ${ }^{3,13}$. However, it should take in account that these studies considered different $\mathrm{CC}$ subdivisions, which included between two and seven regions of analysis. Moreover, Griffin et al. ${ }^{14}$ showed no significant differences between the FA values in MS patients and controls. However, these results have to be interpreted cautiously, as the study sample included both the NAWM of the CC and others areas of NAWM outside of the CC. In fact, the contradictory results regarding the evaluation of the CC with DTI, as demonstrated above, could be related to the different DTI techniques and parameters used in the studies, as well as to the heterogeneity of composition of the fibers crossing the corpus callosum. In our series we observed global FA reduction in the CC, being statistically significant in the rostrum, body and splenium.

It is already known that thin fibers and small axons are preferentially susceptible to injury in MS patients, ${ }^{6,15}$. Also, it is notable from pathological studies that the total number of axons crossing the CC in MS patients is significantly reduced in all the regions of the $\mathrm{CC}^{16}$. In addition, $\mathrm{CC}$ atrophy is associated with clinical disabilities in RRMS and secondary-progressive $\mathrm{MS}^{17}$. Arboitz et al. ${ }^{18}$, in a prospective study, suggested a distinguished fiber composition of the CC. They observed that thin fibers are denser in the splenium and in the genu and decrease to a minimum towards midboby and the posterior region of the CC. Thick fibers are complementary and have a density peak in the posterior midbody.

In addition to the differences in regional fiber composition of the CC, other explanations for the reduced anisotropy in MS patients were suggested in histopathological studies ${ }^{3,4,15}$. One reasonable possibility is related to the Wallerian degeneration of axons transected in MS lesions, which could affect the anisotrophy of the $\mathrm{CC}^{15}$. This hypothesis was supported by one study that demonstrated correlation between regional hemispheric lesion volume and axonal density in its corresponding projection of the $\mathrm{CC}^{3}$. Another study, performed with postmortem brains of MS patients, proposed that the FA decrease primarily reflects the reduction of the myelin content, while axonal damage and gliosis may also affect it in a lesser degree. Moreover, the network of gliotic fibers appears to restrict the disorganization of such loss, limiting the magnitude of FA alterations in MS patients ${ }^{4}$. Both hypotheses are reasonable, and further studies should be conducted to better stress the histopathological causes of the anisotropy reduction in the CC of MS patients.

In the present series, we evaluated the anisotropy of the corpus callosum of MS patients with DTI, dividing the CC structure in five segments: rostrum, genu, anterior and posterior body and splenium. In all these regions the
FA values were lower in the MS patients compared with the controls, being statistically significant in the rostrum ( 0.720 vs 0.819 ), anterior body ( 0.698 vs 0.752 ), posterior body ( 0.711 vs 0.759 ) and splenium ( 0.720 vs 0.880 ). Although we didn't perform correlations between the FA values of the different $C C$ segments with the lesion loading related to the MS in the correspondent areas of the brain white matter, we believe that the reduction of the CC anisotropy could be related to an association of myelin content loss, axonal damage and gliosis.

Our study has some weaknesses. First, we have included a small number of patients considering that the MS is a relatively frequent disease. In addition, most of the patients were receiving immunomodulating medication before entry in the study, and these drugs may, theoretically, affect the anisotropy measurements. Also, we have not compared the anisotropy values with clinical data of the patients, such as the EDSS. This comparison could provide additional insights about the importance of the DTI for the evaluation of MS patients. Finally, the ROI based analysis of the CC has some drawbacks, since the ROIs are subjectively positioned and the images of the different patients are not co-registered. As a result, although the ROIs were positioned in the same $\mathrm{CC}$ segments in each patient, the positions could not be exactly identical. Also, because some portions of the $\mathrm{CC}$, such as the rostrum and the body, have small area in the sagittal plane, partial volume effects of the liquor spaces cannot be totally excluded.

In conclusion, DTI is a promising MR technique to evaluate the NAWM in patients with multiple sclerosis. In this series we found a significant decrease in the FA in all regions of the normal-appearing corpus callosum, being significant in the rostrum, body and splenium, suggesting that there is a subtle and diffuse abnormality in the CC despite its normal appearance on conventional MR imaging. As a result, anisotropy measurement makes possible the assessment of early stage white matter lesions, which are not seen on conventional MR imaging sequences. Because the corpus callosum is composed of compacted interhemispheric fibers transversing a large amount of subcortical white matter, the effects of myelin content loss, axonal damage and gliosis will be more severe in this structure, compared with lobar normal-appearing lobar white matter. Since the DTI is sensitive to microstructural damage in normal-appearing corpus callosum, further studies with this technique could help better evaluation of therapeutic options and prognosis of patients with multiple sclerosis.

\section{REFERENCES}

1. Hasan KM, Gupta RK, Santos RM, Wolinsky JS, Narayana PA. Diffusion tensor fractional anisotropy of the normal-appearing seven segments of the corpus callosum in healthy adults and relapsing-remitting multiple sclerosis patients. J Magn Reson Imaging 2005;21:735-743. 
2. Hofer S, Frahm J. Topography of the human corpus callosum revisited: comprehensive fiber tractography using diffusion tensor magnetic resonance imaging. NeuroImage 2006;32:989-994.

3. Ciccarelli O, Werring DJ, Barker GJ, et al. A study of the mechanisms of normal-appearing white-matter damage in multiple sclerosis using diffusion tensor imaging. J Neurol 2003;250:287-292.

4. Schmierer K, Wheeler-Kingshott CAM, Boulby PA, et al. Diffusion tensor imaging of post mortem multiple sclerosis brain. NeuroImage 2007; 35:467-477.

5. Coombs BD, Best A, Brown MS, et al. Multiple sclerosis pathology in the normal and abnormal appearing white matter of the corpus callosum by diffusion tensor imaging. Multiple Sclerosis 2004;10:392-397.

6. Ge Y, Law M, Johnson G, et al. Preferential occult injury of corpus callosum in multiple sclerosis measured by diffusion tensor imaging. J Magn Reson Imaging 2004;20:1-7.

7. Melhem ER, Mori S, Mukundan G, Kraut MA, Pomper MG, Van Zijl PCM. Diffusion tensor MR imaging of the brain and white matter tractography. AJR 2002;178:3-16.

8. Jellison BJ, Field AS, Medow J, Lazar M, Shariar Salamat M, Alexander AL. Diffusion tensor imaging of cerebral white matter: a pictorial review of physics, fiber tract anatomy, and tumor imaging patterns. AJNR 2004;25:356-369.

9. Guo AC, MacFall JR, Provenzale JM. Multiple sclerosis: diffusion tensor MR imaging for evaluation of normal-appearing white matter. Radiology 2002;222:729-736.
10. Kealey SM, Kim YJ, Provenzale JM. Redefinition of multiple sclerosis plaque size using diffusion tensor MRI. AJR 2004;183:497-503.

11. Andrade RE, Gasparetto EL, Cruz LC Jr, et al. Evaluation of white matter in patients with multiple sclerosis through diffusion tensor magnetic resonance imaging. Arq Neuropsiquiatr 2007;65:561-564.

12. McDonald WI, Compston A, Edan G, et al. Recommended diagnostic criteria for multiple sclerosis: guidelines from the International Panel on the diagnosis of multiple sclerosis. Ann Neurol 2001;50:121-127.

13. Cercignani M, Bozzali M, Iannucci G, Comi G, Filippi M. Intra-voxel and inter-voxel coherence in patients with multiple sclerosis assessed using diffusion tensor MRI. J Neurol 2002;249:875-883.

14. Griffin CM, Chard DT, Cicarelli O, et al. Diffusion tensor imaging in early relapsing-remitting multiple sclerosis. Mult Scler 2001;7:290-297.

15. Evangelou N, Esiri MM, Smith S, et al. Quantitative pathological evidence for axonal loss in normal appearing white matter in multiple sclerosis. Ann Neurol 2000;47:391-395.

16. Evangelou N, Konz D, Esiri MM, Smith S, Palace J, Mathews PM. Regional axonal loss in the corpus callosum correlates with cerebral white matter lesion volume and distribution in multiple sclerosis. Brain 2000;123:1845-1849.

17. Figueira FFA, Santos VS, Figueira GMA, Silva ACM. Corpus callosum index: a practical method for long-term follow-up in multiple sclerosis. Arq Neuropsiquiatr 2007;65:931-935.

18. Arboitiz F, Scheibel AB, Fisher RS, Zaidel E. Fiber composition of the humam corpus callosum. Brain Res 1992;598:143-153. 